\title{
Preparation Parameter Analysis and Optimization of Sustainable Asphalt Binder Modified by Waste Rubber and Diatomite
}

\author{
Hanbing Liu, Mengsu Zhang, Yubo Jiao (D), and Liuxu Fu \\ College of Transportation, Jilin University, Changchun 130025, China \\ Correspondence should be addressed to Yubo Jiao; jiaoyb@jlu.edu.cn \\ Received 6 September 2017; Accepted 19 February 2018; Published 25 March 2018
}

Academic Editor: Estokova Adriana

Copyright (c) 2018 Hanbing Liu et al. This is an open access article distributed under the Creative Commons Attribution License, which permits unrestricted use, distribution, and reproduction in any medium, provided the original work is properly cited.

\begin{abstract}
In this study, crumb rubber and diatomite were used to modify asphalt binder. Wet process was adopted as a preparation method, and the corresponding preparation process was determined firstly. The effects of six preparation parameters (crumb rubber concentration, diatomite concentration, shear time, shear speed, shear temperature, and storing time) on properties of modified asphalt binder (penetration at $25^{\circ} \mathrm{C}$, softening point, ductility, viscosity at $135^{\circ} \mathrm{C}$, elastic recovery, and penetration index) were investigated, and multiresponse optimization was conducted using the response surface method. The results revealed that softening points, viscosity, elastic recovery, and penetration index increase, while penetration and ductility decrease with the increase of crumb rubber concentration. Softening points, viscosity, and penetration index increase, while penetration and ductility decrease with the increase of diatomite concentration, which presents little influence on elastic recovery of binder. Shear temperature presented significant effects on penetration, softening point, viscosity, and ductility. Shear speed, shear time, and storing time have similar effects on binder properties because of their similar mechanism of action. Based on the model obtained from the response surface method, optimized preparation parameters corresponding to specific criteria can be determined, which possess favorable accuracy compared with experimental results.
\end{abstract}

\section{Introduction}

Disposal of industrial wastes has become a critical problem in the world under the promotion of environmental management and mission of sustainable development $[1,2]$. Millions of end-of-life tyres (ELTs) are generated each year due to the increasing number of vehicles, which have been regarded as one of the largest and most problematic waste polymeric materials with large quantity and durability [3]. Current researches have shown that crumb rubber (CR) derived from grinding of ELTs into asphalt modification can be an effective modifier for construction and maintenance of asphalt pavement [4]. For one thing, CR-modified asphalt and corresponding mixture possess favorable environmental benefits. Farina et al. [5] demonstrated the environmental results of recycled materials in bituminous mixtures for pavement wearing courses using life cycle assessment (LCA) methodology. Results reveal that the use of wearing course containing asphalt rubber obtained by the wet process presents significant benefits for energy saving, environmental impact, human health, preservation of ecosystems, and minimization of resource depletion. The reductions of the gross energy requirement and global warming potential range between $36 \%$ and $45 \%$ compared with standard paving solutions. Bartolozzi et al. [6] compared the environmental performances between rubberized asphalt pavement and the conventional one. Results show that the global environmental performances of the rubberized asphalt road are improved by $30-40 \%$. La Rosa et al. [7] evaluated the environmental benefit of using recycled waste tyres in mixture with virgin rubber. It can be concluded that addition of ground tyre rubber (GTR) in styreneisoprene-styrene (SIS) formulation considerably reduces the influences in terms of global warming potential, human toxicity, energy consumption, and so on. Yu et al. [8] evaluated the environmental burdens of plastic-rubber asphalt (PRA) mixture and styrene-butadiene-styrene (SBS) asphalt mixture by using a cradle-to-gate LCA model. The results revealed that PRA mixture is more environmental-friendly than SBS asphalt mixture. CR has been proved to be an effective modifier for virgin asphalt. Adding CR into asphalt 
binder can improve its viscosity and elastic properties at high temperature, which can enhance the resistance ability to permanent deformation under traffic load. It can also increase the flexibility of asphalt binder at low temperature, thus making it more capable of resisting low temperature cracking [9-13]. Therefore, recycled ELTs have been widely used as a road-paving material in the world.

Diatomite is a naturally occurring, soft, siliceous sedimentary rock that can be easily crumbled into fine powder. The typical chemical components of diatomite are silica, alumina, and iron oxide [14]. Diatomite has been widely used as a asphalt modifier due to its low cost, large storage, and high absorptive ability [14-18]. The addition of diatomite into asphalt can improve its high temperature performance, storage stability, rutting resistance, and longterm aging resistance. Asphalt mastic modified by diatomite possesses more favorable high and medium temperature performances than that modified by limestone, hydrated lime, and fly ash [16]. However, diatomite-modified asphalt presents some drawbacks such as reducing the thermal conductivity and low temperature deformation ability of asphalt mixture [17]. In order to overcome this limitation, crumb rubber and diatomite can be used as a compound modifier for asphalt binder. Liu et al. [19] investigated the short-term aging properties of diatomite and crumb rubber compound-modified asphalt (DRA). The results revealed that DRA could combine the advantages of diatomite and crumb rubber and achieve better performance in short-term aging resistance than diatomite-modified asphalt (DA) and crumb rubber-modified asphalt (RA).

It is worth noting that different procedures and parameters can be applied to prepare crumb rubber and diatomite compound-modified asphalt binders [20]. The different preparation procedures and parameters can result in different interactions among crumb rubber, asphalt, and diatomite, thus affecting the properties of modified asphalt. But previous studies have rarely investigated the effect of preparation factors on the property of crumb rubber and diatomite compound-modified asphalt, and even the influences of preparation factors on properties of crumb rubber-modified asphalt and diatomite-modified asphalt are limited [20, 21].

In general, there are two kinds of production methods for crumb rubber-modified asphalt binder: the dry process and wet process $[3,22]$. In the dry process, coarse crumb rubber is used to substitute a part of the mineral aggregate, which is suitable for producing asphalt mixture with favorable elasticity and anti-icing properties. In the wet process, crumb rubber and asphalt are mixed and allowed to react for a period that can take advantage of the benefits of both base ingredients. Crumb rubber-modified asphalt obtained through the wet process has spread worldwide and got much success by roads built in the past 30 years [3]. For the production of diatomite-modified asphalt, the wet process is the most widely used method. In the preparation of both crumb rubber-modified asphalt binder and diatomite-modified one, the device of high-speed mixing and shear stirring is usually adopted to obtain a homogeneous asphalt binder. The processing parameters including temperature, time, and speed determine the interaction condition, which is important for the properties of modified asphalt [23]. However, different preparation parameters were applied in recent researches. For the preparation of crumb rubber-modified asphalt, shear temperature $175^{\circ} \mathrm{C}$, shear speed $5000 \mathrm{rpm}$, and shear time $40 \mathrm{~min}$ were adopted by Wang et al. [24]. Shear temperature $170-180^{\circ} \mathrm{C}$, shear speed $5000 \mathrm{rpm}$, and shear time $5 \mathrm{~min}$ were used by Kedarisetty et al. [23]. In the research by Peralta et al. [25], asphalt rubber binder was heated at $180^{\circ} \mathrm{C}$ for $60 \mathrm{~min}$ and stirred at $230 \mathrm{rpm}$. For the preparation of diatomitemodified asphalt, the shear temperature is $150^{\circ} \mathrm{C}$, shear speed is $3000 \mathrm{rpm}$, and shear time is $120 \mathrm{~min}$ in the research by Cong et al. [14]. The shear temperature is $150^{\circ} \mathrm{C}$, shear speed is $4000 \mathrm{rpm}$, and shear time is $40 \mathrm{~min}$ in the research by Guo et al. [17]. The shear temperature is $160^{\circ} \mathrm{C}$, shear speed is $5000 \mathrm{rpm}$, and shear time is $40 \mathrm{~min}$ in the research by Tan et al. [15]. As can be concluded from current researches, different preparation parameters were adopted. The effects of preparation parameters on properties of modified asphalt have not been demonstrated.

In this study, the preparation process for crumb rubber and diatomite compound-modified asphalt binder was determined. The effects of six kinds of preparation parameters (crumb rubber concentration, diatomite concentration, shear time, shear speed, shear temperature, and storing time) on properties of binder (penetration at $25^{\circ} \mathrm{C}$, softening point, ductility, viscosity at $135^{\circ} \mathrm{C}$, elastic recovery, and penetration index (PI)) were investigated using the response surface method (RSM). Relationships between preparation parameters and asphalt properties were obtained, and multiresponse optimization was conducted to determine the optimum preparation parameters corresponding to the satisfactory properties.

\section{Materials and Methods}

2.1. Raw Materials. Base asphalt AH-90 from Panjin Petrochemical Industry, crumb rubber particle from Changchun Yuxing Rubber Materials Co., Ltd., and diatomite produced by Changchun Diatomite Products Co., Ltd. were used in this study. The detailed properties for raw materials were given in [19].

\subsection{Preparation of Crumb Rubber and Diatomite} Compound-Modified Asphalt. The wet process was adopted to prepare the crumb rubber and diatomite compoundmodified asphalt. A high-speed shear homogenizer (KRH-I, Shanghai Konmix Mechanical \& Electrical Equipment Technology Co. Ltd., China) was employed, which can control its internal temperature through a heating device and oil bath. The preparation process mainly included three steps: heating of raw materials; shearing and mixing of asphalt, crumb rubber, and diatomite; and storing of modified asphalt binder. In this study, the influences of six important preparation parameters on compound-modified asphalt binder were investigated. They were content of crumb rubber by weight of the neat asphalt, content of diatomite by weight of the neat asphalt, shear temperature, 
shear speed, shear time, and storing time. Contents of crumb rubber and diatomite are essential parameters affecting the properties of compound-modified asphalt. Shear speed, shear time, shear temperature, and storing time are key factors in the interaction process among asphalt, crumb rubber, and diatomite to achieve a homogeneous and stable modified binder. The adopted six preparation parameters have not been standardized in current researches, and the researchers have used various parameters. Based on previous research results and considering the workability of binder, the range for content of crumb rubber was $5-15 \%$; it was $5-15 \%$ for content of diatomite, $160-190^{\circ} \mathrm{C}$ for shear temperature, 3000-6000 rpm for shear speed, 30-60 min for shear time, and 30-60 min for storing time in this study. Therefore, the detailed preparation process was determined as follows: firstly, neat asphalt, crumb rubber, and diatomite were separately heated in an oven at $140^{\circ} \mathrm{C}$, and asphalt was at the fluid state that can be easily stirred. Secondly, the crumb rubber and diatomite were added into asphalt, which was placed into a shear homogenizer after preliminary mixing. Then, shear temperature and speed were set to the specific values; the blend of asphalt, crumb rubber, and diatomite was mixed and sheared for the specified shear time after the temperature of the blend reached the specified shear temperature. Finally, the blend was contained in the shear homogenizer to swell for the specified storing time. The crumb rubber and diatomite compound-modified asphalt binder was prepared for the tests.

2.3. Characterization Method. In order to evaluate the effects of content of crumb rubber, content of diatomite, shear temperature, shear speed, shear time, and storing time on asphalt properties, penetration, softening point, ductility, viscosity, elastic recovery, and penetration index (PI) were tested and investigated for compound-modified asphalt binder. Detailed illustrations for penetration, softening point, ductility, viscosity, and elastic recovery were conducted in [19].

The results obtained from penetration and softening point tests can be used to calculate the penetration index (PI). PI is an important property which is related to Van der Poel's monograph and useful to determine the stiffness of asphalt. PI was usually used for the classification of pure asphalt. However, it has been verified to be useful for polymer-modified ones [26]. PI can be calculated by the following classical approach [27]:

$$
\mathrm{PI}=\frac{30}{1+50\left(\lg 800-\lg P_{\left(25^{\circ} \mathrm{C}, 100 \mathrm{~g}, 5 \mathrm{~s}\right)} / T_{\mathrm{R} \& \mathrm{~B}}-25\right)}-10,
$$

where $P_{\left(25^{\circ} \mathrm{C}, 100 \mathrm{~g}, 5 \mathrm{~s}\right)}$ is the penetration at $25^{\circ} \mathrm{C}$ and $T_{\mathrm{R} \& \mathrm{~B}}$ is the softening point temperature.

2.4. Response Surface Method. In order to analyze the effects of six preparation parameters (content of crumb rubber, content of diatomite, shear temperature, shear speed, shear time, and storing time) on the asphalt property, the response surface method (RSM) was utilized. The RSM is a group of mathematical and statistical techniques useful to design experiments. It can save cost and time by reducing the overall number of tests required $[28,29]$. The RSM has been widely used in many areas to identify the effect of individual variables and interaction of different independent variables on the response [30-32]. An optimal quadratic model was used to determine the optimal condition of response:

$$
y=\beta_{0}+\sum_{i=1}^{k} \beta_{i} x_{i}+\sum_{i=1}^{k} \beta_{i i} x_{i}^{2}+\sum_{i<j}^{k} \beta_{i j} x_{i} x_{j}+\varepsilon,
$$

where $y$ is the predicted response; $x_{i}$ and $x_{j}$ are the coded values of the preparation parameters; $k$ is the number of independent variables; $\beta_{i}$ is the linear effect of $x_{i} ; \beta_{i j}$ is the linear interaction between $x_{i}$ and $x_{j} ; \beta_{i i}$ is the secondary effects of $x_{i}$; and $\varepsilon$ is the random error.

In this study, the three level Box-Behnken design with six factors (content of crumb rubber, $X_{1}$; content of diatomite, $X_{2}$; shear time, $X_{3}$; shear speed, $X_{4}$; shear temperature, $X_{5}$; and storing time, $X_{6}$ ) was carried out. Actual and coded values of the independent variables are shown in Table 1. Combinations of $X_{1}(5 \%, 10 \%, 15 \%), X_{2}(5 \%, 10 \%, 15 \%)$, $X_{3}(30,45,60 \mathrm{~min}), X_{4}(3000,4500,6000 \mathrm{rpm}), X_{5}\left(160^{\circ} \mathrm{C}\right.$, $\left.175^{\circ} \mathrm{C}, 190^{\circ} \mathrm{C}\right)$, and $X_{6}(30,45,60 \mathrm{~min})$ were selected as independent variables. Penetration at $25^{\circ} \mathrm{C}, Y_{1}$; softening point, $Y_{2}$; ductility at $15^{\circ} \mathrm{C}, Y_{3}$; viscosity at $135^{\circ} \mathrm{C}, Y_{4}$; elastic recovery at $25^{\circ} \mathrm{C}, Y_{5}$; and penetration index (PI), $Y_{6}$ were adopted as the responses. The software Design-Expert 7.0 was adopted for the scheme design, model generating, statistical analysis, and optimization of the preparation parameters.

\section{Results and Discussion}

\subsection{Experimental Scheme and ANOVA Results}

3.1.1. Experimental Scheme. Experimental scheme for property analysis of compound-modified asphalt binder under the effect of preparation parameters was established based on the RSM. This scheme is composed of 54 experimental groups including 6 replicates at the central point, which is much less than a full test plan $3^{6}=729$. Three specimens are included in each group, and the corresponding average value is regarded as a representative one. The detailed experimental scheme and test results of responses are listed in Table 2. The relationships between independent variables and responses were analyzed by $3 \mathrm{D}$ response surface plots. A $3 \mathrm{D}$ plot is used to represent the dependent variables in function of two independent parameters, when other four variables are kept constant at level 0 in the code value. The interaction between independent variables can also be demonstrated in a $3 \mathrm{D}$ plot.

As can be seen from Table 2, the penetration ranged from 34.8 to $71.0(0.1 \mathrm{~mm})$. Softening point ranged from $46.8^{\circ} \mathrm{C}$ to $62.4^{\circ} \mathrm{C}$. Ductility ranged from 141.0 to $379.7 \mathrm{~mm}$. Viscosity ranged from 497.3 to $5752.0 \mathrm{mPa}$.s. Elastic recovery ranged from $21 \%$ to $63 \%$. PI ranged from -1.5 to 0.83 . According to these experimental ranges, the minimum and maximum values of penetration were obtained at Group 
TABle 1: Actual and coded values of the independent variables.

\begin{tabular}{lcccccc}
\hline \multirow{2}{*}{ Coded value } & \multicolumn{4}{c}{ Actual value } \\
& $X_{1}(\%)$ & $X_{2}(\%)$ & $X_{3}(\mathrm{~min})$ & $X_{4}(\mathrm{rpm})$ & $X_{5}\left({ }^{\circ} \mathrm{C}\right)$ & 160 \\
\hline-1 & 5 & 5 & 30 & 3000 & 30 & 175 \\
0 & 10 & 10 & 45 & 4500 & 6000 & 190 \\
+1 & 15 & 15 & 60 & 60 & 60 \\
\hline
\end{tabular}

nos. $50\left(X_{1}: 15 \% ; X_{2}: 15 \% ; X_{3}: 45 \mathrm{~min} ; X_{4}: 3000 \mathrm{rpm} ; X_{5}\right.$ : $175^{\circ} \mathrm{C}$; and $\left.X_{6}: 45 \mathrm{~min}\right)$ and $46\left(X_{1}: 5 \% ; X_{2}: 5 \% ; X_{3}: 45 \mathrm{~min}\right.$; $X_{4}: 3000 \mathrm{rpm} ; X_{5}: 175^{\circ} \mathrm{C}$; and $\left.X_{6}: 45 \mathrm{~min}\right)$, respectively. The minimum and maximum values of softening point were obtained at Group nos. $46\left(X_{1}: 5 \% ; X_{2}: 5 \% ; X_{3}: 45 \mathrm{~min} ; X_{4}\right.$ : $3000 \mathrm{rpm} ; X_{5}: 175^{\circ} \mathrm{C}$; and $\left.X_{6}: 45 \mathrm{~min}\right)$ and $50\left(X_{1}: 15 \% ; X_{2}\right.$ : $15 \% ; X_{3}: 45 \mathrm{~min} ; X_{4}: 3000 \mathrm{rpm} ; X_{5}: 175^{\circ} \mathrm{C}$; and $\left.X_{6}: 45 \mathrm{~min}\right)$, respectively. The minimum and maximum values of ductility were obtained at Group nos. $54\left(X_{1}: 15 \% ; X_{2}: 10 \% ; X_{3}\right.$ : $45 \mathrm{~min} ; X_{4}: 3000 \mathrm{rpm} ; X_{5}: 160^{\circ} \mathrm{C}$; and $\left.X_{6}: 45 \mathrm{~min}\right)$ and $14\left(X_{1}: 15 \% ; X_{2}: 5 \% ; X_{3}: 45 \mathrm{~min} ; X_{4}: 4500 \mathrm{rpm} ; X_{5}: 190^{\circ} \mathrm{C}\right.$; and $\left.X_{6}: 60 \mathrm{~min}\right)$, respectively. The minimum and maximum values of viscosity were obtained at Group nos. 46 $\left(X_{1}: 5 \% ; X_{2}: 5 \% ; X_{3}: 45 \mathrm{~min} ; X_{4}: 3000 \mathrm{rpm} ; X_{5}: 175^{\circ} \mathrm{C}\right.$; and $\left.X_{6}: 45 \mathrm{~min}\right)$ and $50\left(X_{1}: 15 \% ; X_{2}: 15 \% ; X_{3}: 45 \mathrm{~min} ; X_{4}\right.$ : $3000 \mathrm{rpm} ; X_{5}: 175^{\circ} \mathrm{C}$; and $\left.X_{6}: 45 \mathrm{~min}\right)$, respectively. The minimum and maximum values of elastic recovery were obtained at Group nos. $21\left(X_{1}: 10 \% ; X_{2}: 10 \% ; X_{3}: 45\right.$ min; $X_{4}: 4500 \mathrm{rpm} ; X_{5}: 190^{\circ} \mathrm{C}$; and $\left.X_{6}: 60 \mathrm{~min}\right)$ and $50\left(X_{1}: 15 \%\right.$; $X_{2}: 15 \% ; X_{3}: 45 \mathrm{~min} ; X_{4}: 3000 \mathrm{rpm} ; X_{5}: 175^{\circ} \mathrm{C}$; and $X_{6}$ : $45 \mathrm{~min})$, respectively. The minimum and maximum values of PI were obtained at Group nos. $49\left(X_{1}: 15 \% ; X_{2}: 5 \%\right.$; $X_{3}: 45 \mathrm{~min} ; X_{4}: 3000 \mathrm{rpm} ; X_{5}: 175^{\circ} \mathrm{C}$; and $\left.X_{6}: 45 \mathrm{~min}\right)$ and $7\left(X_{1}: 5 \% ; X_{2}: 10 \% ; X_{3}: 30 \mathrm{~min} ; X_{4}: 4500 \mathrm{rpm} ; X_{5}: 175^{\circ} \mathrm{C}\right.$; and $X_{6}: 60 \mathrm{~min}$ ), respectively.

\subsubsection{Analysis of Variance (ANOVA) Results for Quadratic} Models and Independent Variables. Analysis of variance (ANOVA) was used to evaluate the statistical significance of independent parameters and interactions among them. The adequacy of the models constructed for penetration at $25^{\circ} \mathrm{C}$, softening point, ductility at $15^{\circ} \mathrm{C}$, viscosity at $135^{\circ} \mathrm{C}$, elastic recovery at $25^{\circ} \mathrm{C}$, and penetration index (PI) was checked by coefficient of determination $\left(R^{2}\right)$, adjusted coefficient of determination (Adj. $R^{2}$ ), Adeq. precision, and Fisher's test value $(F$ value). Models and factors were considered significant when $p<0.01$. ANOVA results for quadratic models and independent variables are obtained and listed in Tables 3 and 4, respectively. The detailed explanations of results are given in Sections 3.2-3.7.

\subsection{Penetration}

3.2.1. Analysis of the Model for Penetration. The results of ANOVA for the penetration model indicated that the model possessed satisfactory levels of $R^{2}(0.90)$, Adj. $R^{2}(0.80)$, and Adeq. precision (11.014), which were significant at $p<0.0001$. $R^{2}$ and Adj. $R^{2}$ values of the model were higher than 0.8 , which revealed a close agreement between experimental results and predicted ones. Adeq. precision is the measure of the signal-to-noise ratio, and greater ratio than 4 is desirable. An Adeq. precision of 11.014 indicated that the model can be used to navigate the design space.

The second-order quadratic polynomial models were established based on the regression coefficients that were determined with the least squares method. Stepwise regression was used to identify the statistically significant variables. As can be seen from the ANOVA results of independent variables for the penetration model, the significant variables $(p<0.05)$ for the penetration model included $X_{1}, X_{2}, X_{5}, X_{23}, X_{46}, X_{22}, X_{33}$, and $X_{44}$. The reduced secondorder model in terms of coded factors for penetration was obtained by removing the insignificant variables:

$$
\begin{aligned}
Y_{1}= & 43.81-6.69 \times X_{1}-4.97 \times X_{2}+5.17 \times X_{5} \\
& +3.10 \times X_{23}-3.01 \times X_{46}+2.87 \times X_{22}+6.24 \times X_{33} \\
& +6.22 \times X_{44} .
\end{aligned}
$$

3.2.2. Effect of Preparation Parameters on Penetration. As shown in Table 4, the most significant linear variables on penetration include content of crumb rubber, content of diatomite, and shear temperature with $p<0.0001$. Meanwhile, quadratic terms of shear time and shear speed present the most significant effect with $p<0.0001$. The quadratic term of diatomite content has a significant effect with $p<0.05$. Furthermore, the interaction terms of (diatomite content) $*$ (shear time) and (shear speed) $*$ (storing time) have significant effects on penetration with $p<0.05$.

The relationships between preparation parameters and penetration were demonstrated in $3 \mathrm{D}$ response surface plots, which are shown in Figure 1. As can be seen from the figure, the penetration decreases with the increase of diatomite concentration and crumb rubber concentration. However, it increases with the increase of shear temperature. For the relationships of penetration with shear time, shear speed, and storing time, they present the trends of decreasing firstly and then increasing.

The interaction of crumb rubber and asphalt binder is essential for the performance of modified asphalt binder. Rubber particle swelling and significant absorption take place when rubber particles are added into heated asphalt binder. The polymer chains of rubber particles can absorb the lighter and solvating fractions of binder. Rubber particle size and shape are changed, and a gel-like structure is generated [3], which causes the reduction of penetration for asphalt binder.

Diatomite has a large specific area and good adsorption performance, which can effectively absorb the lower molecular group and lower polar aromatic molecular group for its mesoporous structure. The anchorage structure forms 
TABLE 2: Experimental scheme with test results for property analysis of compound-modified asphalt binder.

\begin{tabular}{|c|c|c|c|c|c|c|c|c|c|c|c|c|}
\hline \multirow{2}{*}{$\begin{array}{l}\text { Group } \\
\text { number }\end{array}$} & \multicolumn{6}{|c|}{ Preparation parameters } & \multicolumn{6}{|c|}{ Responses } \\
\hline & $X_{1}(\%)$ & $X_{2}(\%)$ & $X_{3}(\min )$ & $X_{4}(\mathrm{rpm})$ & $X_{5}\left({ }^{\circ} \mathrm{C}\right)$ & $X_{6}(\min )$ & $Y_{1}(0.1 \mathrm{~mm})$ & $Y_{2}\left({ }^{\circ} \mathrm{C}\right)$ & $Y_{3}(\mathrm{~mm})$ & $Y_{4}(\mathrm{mPa} \cdot \mathrm{s})$ & $Y_{5}(\%)$ & $Y_{6}$ \\
\hline 1 & 5 & 10 & 45 & 6000 & 160 & 45 & 47.9 & 52.5 & 185.0 & 1343.3 & 33 & -0.69 \\
\hline 2 & 15 & 10 & 30 & 4500 & 175 & 30 & 47.5 & 56.2 & 218.3 & 2682.3 & 49 & 0.12 \\
\hline 3 & 10 & 5 & 30 & 4500 & 190 & 45 & 67.7 & 50.5 & 339.5 & 1280.0 & 36 & -0.33 \\
\hline 4 & 15 & 5 & 45 & 6000 & 175 & 45 & 51.0 & 57.2 & 259.0 & 2865.0 & 58 & 0.50 \\
\hline 5 & 10 & 15 & 45 & 4500 & 160 & 30 & 42.6 & 55.4 & 158.3 & 2098.0 & 36 & -0.31 \\
\hline 6 & 10 & 10 & 45 & 4500 & 175 & 45 & 44.8 & 53.3 & 203.3 & 1907.0 & 43 & -0.66 \\
\hline 7 & 5 & 10 & 30 & 4500 & 175 & 60 & 60.8 & 47.1 & 295.0 & 692.4 & 25 & -1.50 \\
\hline 8 & 10 & 10 & 45 & 4500 & 175 & 45 & 42.4 & 54.5 & 205.6 & 1919.0 & 44 & -0.52 \\
\hline 9 & 10 & 15 & 30 & 4500 & 190 & 45 & 50.6 & 54.8 & 294.3 & 1792.7 & 42 & -0.04 \\
\hline 10 & 10 & 10 & 45 & 4500 & 175 & 45 & 44.3 & 53.9 & 203.3 & 1907.0 & 43 & -0.55 \\
\hline 11 & 15 & 10 & 30 & 4500 & 175 & 60 & 51.4 & 55.1 & 244.0 & 1778.7 & 44 & 0.07 \\
\hline 12 & 10 & 10 & 45 & 4500 & 175 & 45 & 43.6 & 53.9 & 204.5 & 1906.0 & 44 & -0.58 \\
\hline 13 & 10 & 5 & 45 & 4500 & 160 & 60 & 45.3 & 53.1 & 181.5 & 1833.3 & 42 & -0.68 \\
\hline 14 & 10 & 5 & 45 & 4500 & 190 & 60 & 55.0 & 51.0 & 379.7 & 1676.0 & 41 & -0.73 \\
\hline 15 & 10 & 10 & 30 & 3000 & 175 & 30 & 55.5 & 54.1 & 215.5 & 1844.7 & 34 & 0.03 \\
\hline 16 & 5 & 10 & 30 & 4500 & 175 & 30 & 54.6 & 51.2 & 255.7 & 1140.7 & 25 & -0.70 \\
\hline 17 & 10 & 10 & 45 & 4500 & 175 & 45 & 43.1 & 54.1 & 204.9 & 1906.5 & 44 & -0.57 \\
\hline 18 & 10 & 15 & 60 & 4500 & 190 & 45 & 56.9 & 55.3 & 197.0 & 2017.0 & 51 & 0.36 \\
\hline 19 & 10 & 5 & 30 & 4500 & 160 & 45 & 53.1 & 53.6 & 175.0 & 1402.0 & 40 & -0.20 \\
\hline 20 & 10 & 15 & 30 & 4500 & 160 & 45 & 41.8 & 55.9 & 171.0 & 2513.0 & 36 & -0.24 \\
\hline 21 & 10 & 10 & 30 & 3000 & 175 & 60 & 58.8 & 51.8 & 316.5 & 1301.7 & 21 & -0.37 \\
\hline 22 & 10 & 10 & 45 & 4500 & 175 & 45 & 44.8 & 53.3 & 203.3 & 1907.0 & 43 & -0.66 \\
\hline 23 & 10 & 5 & 60 & 4500 & 190 & 45 & 61.6 & 50.5 & 301.0 & 953.1 & 41 & -0.58 \\
\hline 24 & 5 & 5 & 45 & 6000 & 175 & 45 & 68.6 & 50.6 & 284.0 & 770.1 & 31 & -0.27 \\
\hline 25 & 15 & 10 & 45 & 6000 & 160 & 45 & 36.9 & 59.6 & 172.7 & 3821.0 & 54 & 0.24 \\
\hline 26 & 10 & 5 & 60 & 4500 & 160 & 45 & 47.8 & 52.7 & 184.0 & 1034.0 & 46 & -0.65 \\
\hline 27 & 5 & 10 & 45 & 3000 & 160 & 45 & 54.6 & 50.7 & 219.3 & 880.4 & 27 & -0.82 \\
\hline 28 & 10 & 10 & 30 & 6000 & 175 & 60 & 53.8 & 54.2 & 231.0 & 2008.3 & 38 & -0.02 \\
\hline 29 & 10 & 15 & 45 & 4500 & 190 & 60 & 53.1 & 55.4 & 243.5 & 2109.0 & 53 & 0.21 \\
\hline 30 & 15 & 10 & 60 & 4500 & 175 & 30 & 43.6 & 59.2 & 214.3 & 3675.7 & 57 & 0.54 \\
\hline 31 & 5 & 15 & 45 & 6000 & 175 & 45 & 48.8 & 53.2 & 216.3 & 1356.0 & 29 & -0.50 \\
\hline 32 & 10 & 5 & 45 & 4500 & 190 & 30 & 56.8 & 51.4 & 341.3 & 1627.0 & 42 & -0.55 \\
\hline 33 & 10 & 10 & 60 & 6000 & 175 & 60 & 56.6 & 52.4 & 308.5 & 1930.3 & 47 & -0.32 \\
\hline 34 & 10 & 10 & 30 & 6000 & 175 & 30 & 57.9 & 52.2 & 354.3 & 1508.0 & 33 & -0.31 \\
\hline 35 & 5 & 10 & 45 & 3000 & 190 & 45 & 63.0 & 49.4 & 315.0 & 1188.0 & 32 & -0.80 \\
\hline 36 & 10 & 10 & 60 & 3000 & 175 & 30 & 53.3 & 54.0 & 269.5 & 2229.7 & 44 & -0.09 \\
\hline 37 & 10 & 15 & 60 & 4500 & 160 & 45 & 49.0 & 56.0 & 174.0 & 2430.0 & 42 & 0.15 \\
\hline 38 & 10 & 15 & 45 & 4500 & 190 & 30 & 49.7 & 54.5 & 260.3 & 2054.0 & 46 & -0.15 \\
\hline 39 & 5 & 10 & 60 & 4500 & 175 & 60 & 49.9 & 50.9 & 249.0 & 913.4 & 34 & -0.99 \\
\hline 40 & 10 & 5 & 45 & 4500 & 160 & 30 & 49.2 & 53.3 & 197.7 & 1860.0 & 41 & -0.44 \\
\hline 41 & 5 & 15 & 45 & 3000 & 175 & 45 & 55.2 & 51.5 & 357.7 & 1202.7 & 15 & -0.60 \\
\hline 42 & 10 & 10 & 60 & 3000 & 175 & 60 & 60.3 & 50.9 & 329.0 & 774.4 & 25 & -0.53 \\
\hline 43 & 5 & 10 & 45 & 6000 & 190 & 45 & 59.3 & 49.9 & 314.5 & 704.8 & 30 & -0.82 \\
\hline 44 & 15 & 15 & 45 & 6000 & 175 & 45 & 37.1 & 60.4 & 191.7 & 4847.3 & 61 & 0.40 \\
\hline 45 & 10 & 10 & 60 & 6000 & 175 & 30 & 66.3 & 49.5 & 348.0 & 1735.0 & 41 & -0.65 \\
\hline 46 & 5 & 5 & 45 & 3000 & 175 & 45 & 71.0 & 46.8 & 307.3 & 497.3 & 23 & -1.21 \\
\hline 47 & 15 & 10 & 45 & 3000 & 190 & 45 & 50.6 & 57.6 & 292.3 & 3509.0 & 54 & 0.57 \\
\hline 48 & 15 & 10 & 45 & 6000 & 190 & 45 & 47.0 & 57.0 & 278.3 & 3539.0 & 60 & 0.26 \\
\hline 49 & 15 & 5 & 45 & 3000 & 175 & 45 & 50.8 & 58.8 & 224.5 & 3724.3 & 55 & 0.83 \\
\hline 50 & 15 & 15 & 45 & 3000 & 175 & 45 & 34.8 & 62.4 & 160.0 & 5752.0 & 63 & 0.64 \\
\hline 51 & 10 & 15 & 45 & 4500 & 160 & 60 & 39.1 & 55.6 & 170.0 & 2198.7 & 32 & -0.45 \\
\hline 52 & 5 & 10 & 60 & 4500 & 175 & 30 & 58.4 & 49.1 & 309.5 & 765.9 & 23 & -1.07 \\
\hline 53 & 15 & 10 & 60 & 4500 & 175 & 60 & 40.6 & 59.5 & 198.7 & 4491.7 & 59 & 0.43 \\
\hline 54 & 15 & 10 & 45 & 3000 & 160 & 45 & 40.2 & 59.3 & 141.0 & 3916.3 & 45 & 0.37 \\
\hline
\end{tabular}

and the stiffening effect presents [33], which decrease the penetration of binder.

As for shear temperature, the interactions among asphalt, crumb rubber, and diatomite are strengthened with the increase of shear temperature. Rubber particle dissolution happens because of depolymerization and devulcanization, which break not only the polymer chains of rubber but also the crosslink bonds. Then, the swelling reaction is reduced, 
TABLE 3: ANOVA results for quadratic models of modified asphalt properties.

\begin{tabular}{|c|c|c|c|c|c|c|}
\hline Sources & $R^{2}$ & Adj. $R^{2}$ & Adeq. precision & $F$ value & $p$ value & Significant \\
\hline$Y_{1}$ & 0.90 & 0.80 & 11.014 & 8.68 & $<0.0001$ & Yes \\
\hline$Y_{2}$ & 0.95 & 0.90 & 17.854 & 18.37 & $<0.0001$ & Yes \\
\hline$Y_{3}$ & 0.90 & 0.79 & 10.875 & 8.46 & $<0.0001$ & Yes \\
\hline$Y_{4}$ & 0.94 & 0.87 & 13.392 & 13.94 & $<0.0001$ & Yes \\
\hline$Y_{5}^{4}$ & 0.92 & 0.84 & 14.374 & 11.01 & $<0.0001$ & Yes \\
\hline$Y_{6}$ & 0.93 & 0.85 & 14.466 & 12.00 & $<0.0001$ & Yes \\
\hline
\end{tabular}

TABLE 4: ANOVA results for independent variables.

\begin{tabular}{|c|c|c|c|c|c|c|c|c|c|c|c|c|}
\hline \multirow{2}{*}{ Sources } & \multicolumn{2}{|r|}{$Y_{1}$} & \multicolumn{2}{|r|}{$Y_{2}$} & \multicolumn{2}{|r|}{$Y_{3}$} & \multicolumn{2}{|r|}{$Y_{4}$} & \multicolumn{2}{|r|}{$Y_{5}$} & \multicolumn{2}{|r|}{$Y_{6}$} \\
\hline & $F$ & $p$ & $F$ & $p$ & $F$ & $p$ & $F$ & $p$ & $F$ & $p$ & $F$ & $p$ \\
\hline$X_{1}$ & 74.86 & $<0.0001^{* * * *}$ & 358.54 & $<0.0001^{* * * *}$ & 26.1 & $<0.0001^{* * * *}$ & 220.32 & $<0.0001^{* * * *}$ & 279.97 & $<0.0001^{* * * *}$ & 236.0 & $<0.0001^{* * * *}$ \\
\hline$X_{2}$ & 41.34 & $<0.0001^{* * * *}$ & 60.43 & $<0.0001^{* * * *}$ & 17.3 & $0.0003^{* * *}$ & 23.60 & $<0.0001^{* * * *}$ & 0.19 & 0.6701 & 15.2 & $0.0006^{* * *}$ \\
\hline$X_{3}$ & 0.26 & 0.6144 & 0.38 & 0.5416 & 0.0 & 0.8445 & 1.81 & 0.1899 & 19.69 & $0.0001^{* * * *}$ & 0.0 & 0.9208 \\
\hline$X_{4}$ & 0.84 & 0.3668 & 0.07 & 0.7993 & 0.0 & 0.9755 & 0.03 & 0.8620 & 15.23 & $0.0006^{* * *}$ & 0.0 & 0.8415 \\
\hline$X_{5}$ & 44.66 & $<0.0001^{* * * *}$ & 15.07 & $0.0006^{* * *}$ & 104.4 & $<0.0001^{* * * *}$ & 1.66 & 0.2085 & 6.66 & $0.0159^{*}$ & 1.4 & 0.2500 \\
\hline$X_{6}$ & 0.33 & 0.5691 & 0.36 & 0.5541 & 0.0 & 0.9802 & 0.46 & 0.5041 & 0.24 & 0.6299 & 1.8 & 0.1901 \\
\hline$X_{12}$ & 0.27 & 0.6055 & 0.02 & 0.8832 & 2.0 & 0.1675 & 4.45 & $0.0448^{*}$ & 2.78 & 0.1077 & 1.4 & 0.2395 \\
\hline$X_{13}$ & 0.49 & 0.4923 & 3.59 & 0.0692 & 0.5 & 0.4847 & 8.96 & $0.0060^{* *}$ & 2.33 & 0.1388 & 1.3 & 0.2606 \\
\hline$X_{14}$ & 0.98 & 0.3306 & 7.37 & $0.0116^{*}$ & 6.2 & $0.0197^{* *}$ & 1.50 & 0.2312 & 0.35 & 0.5609 & 7.2 & $0.0125^{*}$ \\
\hline$X_{15}$ & 0.00 & 0.9454 & 0.02 & 0.8961 & 0.2 & 0.6962 & 0.08 & 0.7832 & 1.16 & 0.2905 & 0.4 & 0.5503 \\
\hline$X_{16}$ & 0.09 & 0.7717 & 0.26 & 0.6137 & 0.1 & 0.7023 & 0.03 & 0.8700 & 1.59 & 0.2184 & 1.1 & 0.3138 \\
\hline$X_{23}$ & 5.37 & $0.0286^{*}$ & 0.24 & 0.6252 & 0.6 & 0.4287 & 0.42 & 0.5223 & 0.14 & 0.7099 & 7.0 & $0.0134^{*}$ \\
\hline$X_{24}$ & 0.03 & 0.8562 & 0.71 & 0.4083 & 2.2 & 0.1461 & 0.02 & 0.8992 & 0.00 & 0.9543 & 1.8 & 0.1916 \\
\hline$X_{25}$ & 0.27 & 0.6110 & 2.23 & 0.1478 & 7.0 & $0.0137^{* *}$ & 0.14 & 0.7147 & 11.70 & $0.0021^{* *}$ & 3.4 & 0.0758 \\
\hline$X_{26}$ & 0.28 & 0.6017 & 0.31 & 0.5800 & 0.1 & 0.7374 & 0.01 & 0.9184 & 0.07 & 0.7989 & 1.3 & 0.2724 \\
\hline$X_{34}$ & 1.23 & 0.2783 & 1.33 & 0.2591 & 0.0 & 0.9543 & 0.05 & 0.8231 & 0.11 & 0.7442 & 0.4 & 0.5388 \\
\hline$X_{35}$ & 0.03 & 0.8635 & 0.18 & 0.6718 & 3.4 & 0.0782 & 0.07 & 0.7891 & 0.02 & 0.8861 & 0.2 & 0.6993 \\
\hline$X_{36}$ & 2.40 & 0.1332 & 2.93 & 0.0986 & 0.8 & 0.3941 & 0.36 & 0.5522 & 0.48 & 0.4967 & 1.1 & 0.3038 \\
\hline$X_{45}$ & 0.07 & 0.8001 & 0.53 & 0.4748 & 0.0 & 0.8845 & 0.41 & 0.5299 & 0.68 & 0.4156 & 0.3 & 0.5728 \\
\hline$X_{46}$ & 5.05 & $0.0334^{*}$ & 11.53 & $0.0022^{* *}$ & 16.1 & $0.0005^{* * *}$ & 4.37 & $0.0466^{*}$ & 12.78 & $0.0014^{* *}$ & 6.7 & $0.0158^{*}$ \\
\hline$X_{56}$ & 0.70 & 0.4095 & 0.03 & 0.8704 & 0.1 & 0.7497 & 0.00 & 0.9816 & 0.46 & 0.5027 & 1.0 & 0.3236 \\
\hline$X_{11}$ & 0.39 & 0.5398 & 7.87 & $0.0094^{* *}$ & 0.4 & 0.5287 & 10.11 & $0.0038^{* *}$ & 0.84 & 0.3692 & 3.6 & 0.0693 \\
\hline$X_{22}$ & 5.90 & $0.0223^{*}$ & 2.61 & 0.1183 & 0.9 & 0.3585 & 1.37 & 0.2530 & 0.10 & 0.7563 & 13.0 & $0.0013^{* *}$ \\
\hline$X_{33}$ & 27.96 & $<0.0001^{* * * *}$ & 3.72 & 0.0647 & 4.3 & $0.0471^{*}$ & 4.40 & $0.0458^{*}$ & 3.92 & 0.0585 & 5.1 & $0.0318^{*}$ \\
\hline$X_{44}$ & 27.76 & $<0.0001^{* * * *}$ & 0.38 & 0.5442 & 23.2 & $<0.0001^{* * * *}$ & 0.50 & 0.4840 & 5.90 & $0.0224^{*}$ & 13.0 & $0.0013^{* *}$ \\
\hline$X_{55}$ & 0.29 & 0.5974 & 0.04 & 0.8452 & 0.0 & 0.8253 & 0.47 & 0.4968 & 0.09 & 0.7687 & 0.3 & 0.5725 \\
\hline$X_{66}$ & 1.71 & 0.2025 & 3.17 & 0.0869 & 11.8 & $0.0020^{* *}$ & 0.10 & 0.7596 & 3.99 & 0.0562 & 0.8 & 0.3675 \\
\hline
\end{tabular}

Note. ${ }^{*} p \leq 0.05,{ }^{* *} p \leq 0.01,{ }^{* * *} p \leq 0.001$, and ${ }^{* * * *} p \leq 0.0001$.

and the lighter fractions of binder increase. Therefore, the penetration increases with the increase of shear temperature.

Shear speed, shear time, and storing time present similar effects on penetration. At the early stage, rubber and diatomite particles are distributed more evenly in asphalt binder with the increase of shear speed, shear time, and storing time. The swelling effect is significant, and distances between particles are shortened. A gel-like structure and an anchorage structure are formed and strengthened. The penetration decreases. However, the crosslink bonds between particles are destroyed if the shear time and storing time are longer and the shear speed becomes higher, which increase the penetration of binder.

\subsection{Softening Point}

3.3.1. Analysis of the Model for Softening Point. The softening point model possessed satisfactory levels of $R^{2}(0.95)$,
Adj. $R^{2}$ (0.90), and Adeq. precision (17.854), which were significant at $p<0.0001 . R^{2}$ and Adj. $R^{2}$ values of the model were higher than 0.8 , which revealed a close agreement between experimental results and predicted ones. An Adeq. precision of 17.854 indicated that the model can be used to navigate the design space.

As can be seen from the ANOVA results of independent variables for the softening point model, the significant variables $(p<0.05)$ included $X_{1}, X_{2}, X_{5}, X_{14}, X_{46}$, and $X_{11}$. The reduced second-order model in terms of coded factors for softening point was obtained by removing the insignificant variables:

$$
\begin{aligned}
Y_{2}= & 53.83+4.15 \times X_{1}+1.70 \times X_{2}-0.85 \times X_{5} \\
& -0.73 \times X_{14}+1.29 \times X_{46}+0.94 \times X_{11} .
\end{aligned}
$$

3.3.2. Effect of Preparation Parameters on Softening Point. As shown in Table 4, the most significant linear 


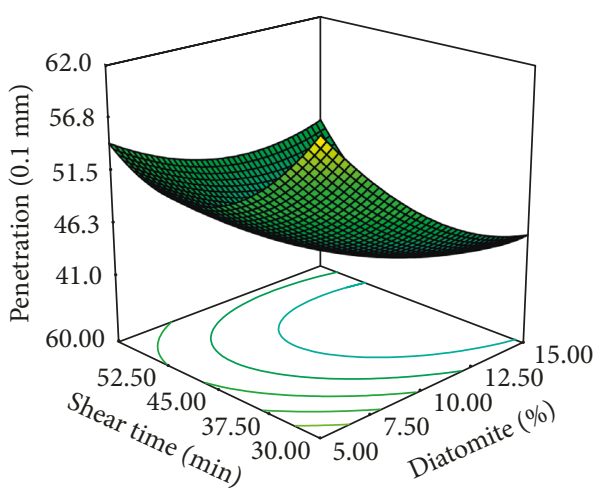

(a)

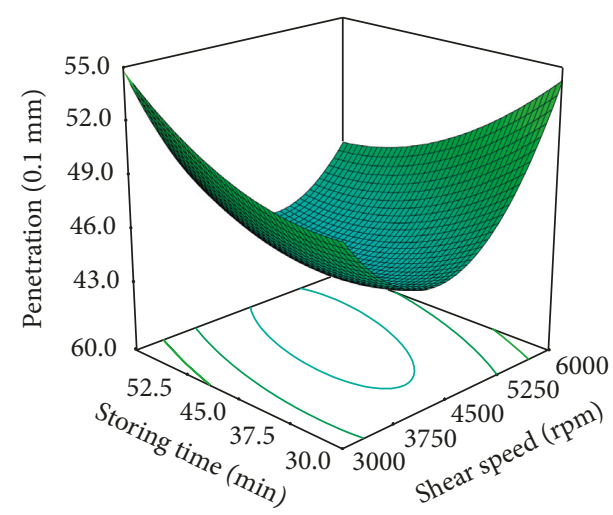

(b)

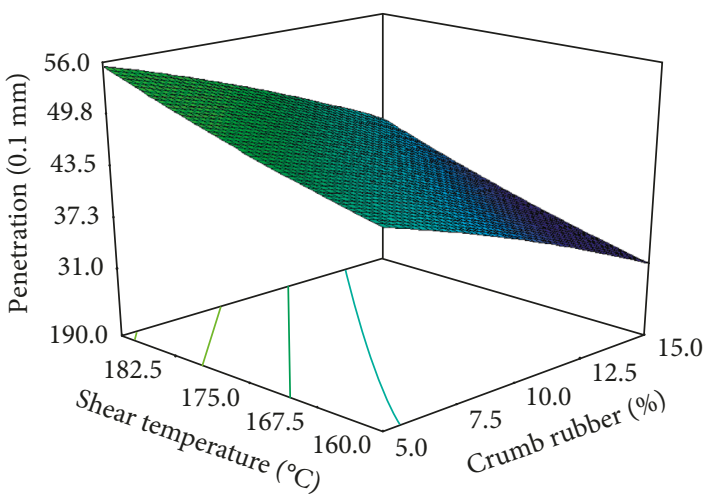

(c)

Figure 1: Response surface plots for the effect of preparation parameters on penetration. (a) Diatomite content $*$ shear time, (b) shear speed $*$ storing time, and $(\mathrm{c})$ crumb rubber content $*$ shear temperature.

variables on softening point include content of crumb rubber and content of diatomite with $p<0.0001$, followed by shear temperature with $p<0.001$. Meanwhile, the quadratic term of crumb rubber content has a significant effect with $p<0.01$. Furthermore, the interaction terms of (shear speed) * (storing time) have significant effects on softening point with $p<0.01$, followed by (crumb rubber content) $*$ (shear speed) with $p<0.05$.

The softening points are applied to evaluate the high stability of modified asphalt binder. The higher the softening point is, the better the high susceptibility of asphalt is. The relationships between preparation parameters and softening point were demonstrated in 3D response surface plots, which are shown in Figure 2. As can be seen from the figure, the softening point increases with the increase of diatomite concentration and crumb rubber concentration. However, it decreases with the increase of shear temperature. For the relationships of the softening point with shear time, shear speed, and storing time, they present the trends of increasing firstly and then decreasing.

As discussed above, the polymer chains of rubber particles can absorb the lighter and solvating fractions of binder, and a gel-like structure is generated, which shortens the distances between particles and increases the softening point of binder. Diatomite can effectively absorb the lower molecular group and lower polar aromatic molecular group.
The anchorage structure can improve the high temperature stability of asphalt binder with the increase of diatomite content. As for shear temperature, higher temperature will lead to the breakdown of polymer chains of rubber and crosslink bonds of binder. Therefore, the softening point increases with the increase of shear temperature. Shear speed, shear time, and storing time can strength the gel-like structure and anchorage structure of asphalt binder at the early stage, which make the softening point increase. However, the crosslink bonds between particles are destroyed if the shear time and storing time are longer and the shear speed becomes higher, which decrease the softening point of binder.

\subsection{Ductility}

3.4.1. Analysis of the Model for Ductility. The ductility model possessed satisfactory levels of $R^{2}(0.90)$, Adj. $R^{2}(0.79)$, and Adeq. precision (10.875), which were significant at $p<0.0001 . R^{2}$ value of the model was higher than 0.8 and Adj. $R^{2}$ value was highly close to 0.8 , which revealed a close agreement between experimental results and predicted ones. An Adeq. precision of 10.875 indicated that the model can be used to navigate the design space.

As can be seen from the ANOVA results of independent variables for the ductility model, the significant variables 


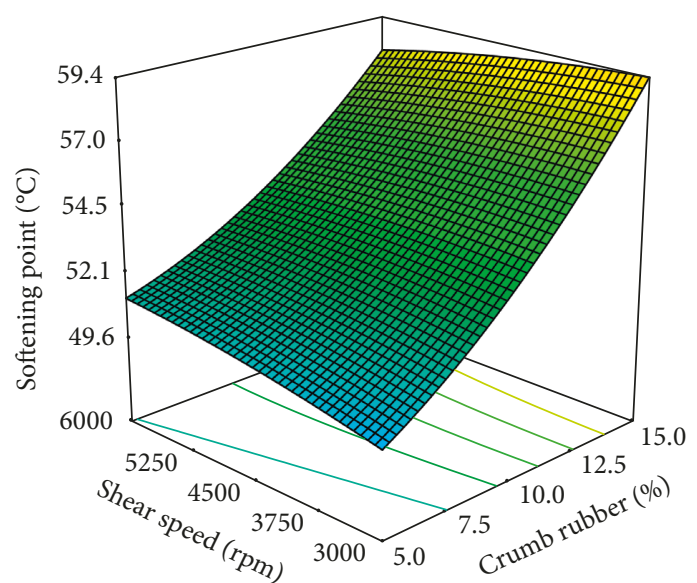

(a)

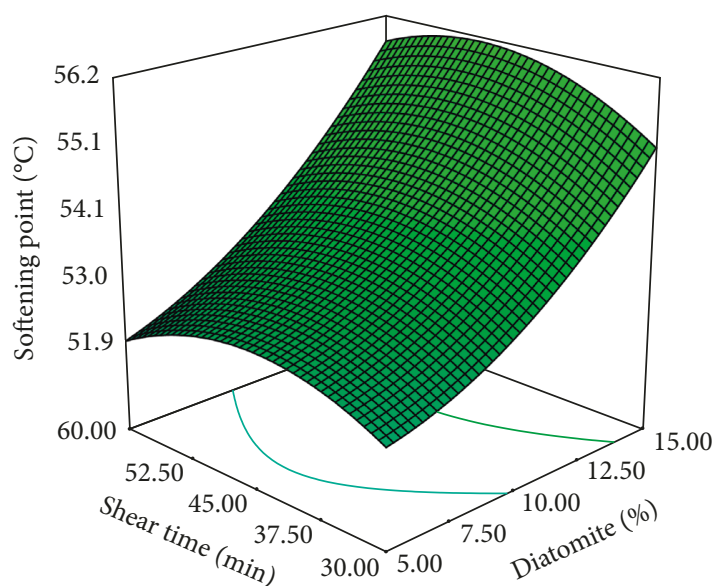

(b)

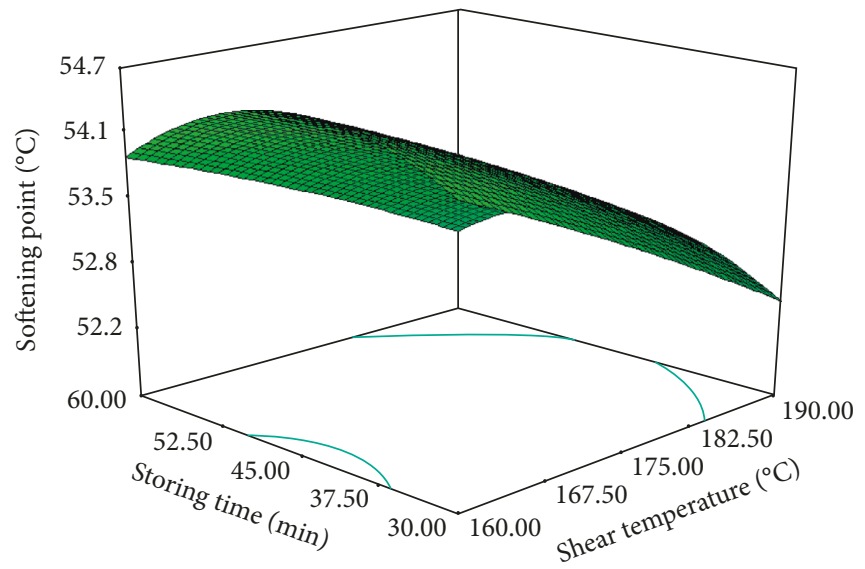

(c)

FiguRE 2: Response surface plots for the effect of preparation parameters on softening point. (a) Crumb rubber content $*$ shear speed, (b) diatomite content $*$ shear time, and (c) shear temperature $*$ storing time.

$(p<0.05)$ included $X_{1}, X_{2}, X_{5}, X_{14}, X_{25}, X_{46}, X_{33}, X_{44}$, and $X_{66}$. The reduced second-order model in terms of coded factors for ductility was obtained by removing the insignificant variables:

$$
\begin{aligned}
Y_{3}= & 204.63-29.73 \times X_{1}-24.18 \times X_{2}+59.47 \times X_{5} \\
& +17.71 \times X_{1} \times X_{4}-18.84 \times X_{25}-40.42 \times X_{46} \\
& +18.53 \times X_{33}+42.80 \times X_{44}+30.59 \times X_{66} .
\end{aligned}
$$

3.4.2. Effect of Preparation Parameters on Ductility. As shown in Table 4, the most significant linear variables on ductility include content of crumb rubber and shear temperature with $p<0.0001$, followed by content of diatomite with $p<0.001$. Meanwhile, the quadratic term of shear speed has a significant effect with $p<0.0001$, followed by storing time with $p<0.001$ and shear time with $p<0.05$. Furthermore, the interaction terms of (shear speed) $*$ (storing time) have significant effects on ductility with $p<0.001$, followed by (crumb rubber content) $*$ (shear speed) and (diatomite content) $*$ (shear temperature) with $p<0.01$.
Ductility can be used to reflect the low temperature performance of asphalt binder. The relationships between preparation parameters and ductility were demonstrated in $3 \mathrm{D}$ response surface plots, which are shown in Figure 3. As can be seen from the figure, the ductility increases with the increase of shear temperature. However, it decreases with the increase of diatomite concentration and crumb rubber concentration. For the relationships of ductility with shear time, shear speed, and storing time, they present the trends of decreasing firstly and then increasing.

The reasons lie in that addition of diatomite and crumb rubber can absorb the lighter fractions of the asphalt and result in large progressive increase of stiffness. The higher the stiffness is, the faster the failure stress reaches [16, 34]. Therefore, the elongation of compound-modified asphalt binder decreases. Another important reason is the stress concentration phenomenon occurring at the interface between the particle and asphalt. Therefore, the reduction of ductility does not indicate that the low temperature performance for crumb rubber and diatomite compound-modified asphalt is unsatisfactory. With the increase of shear temperature, viscosity toughness is reduced, resulting in the increase of 

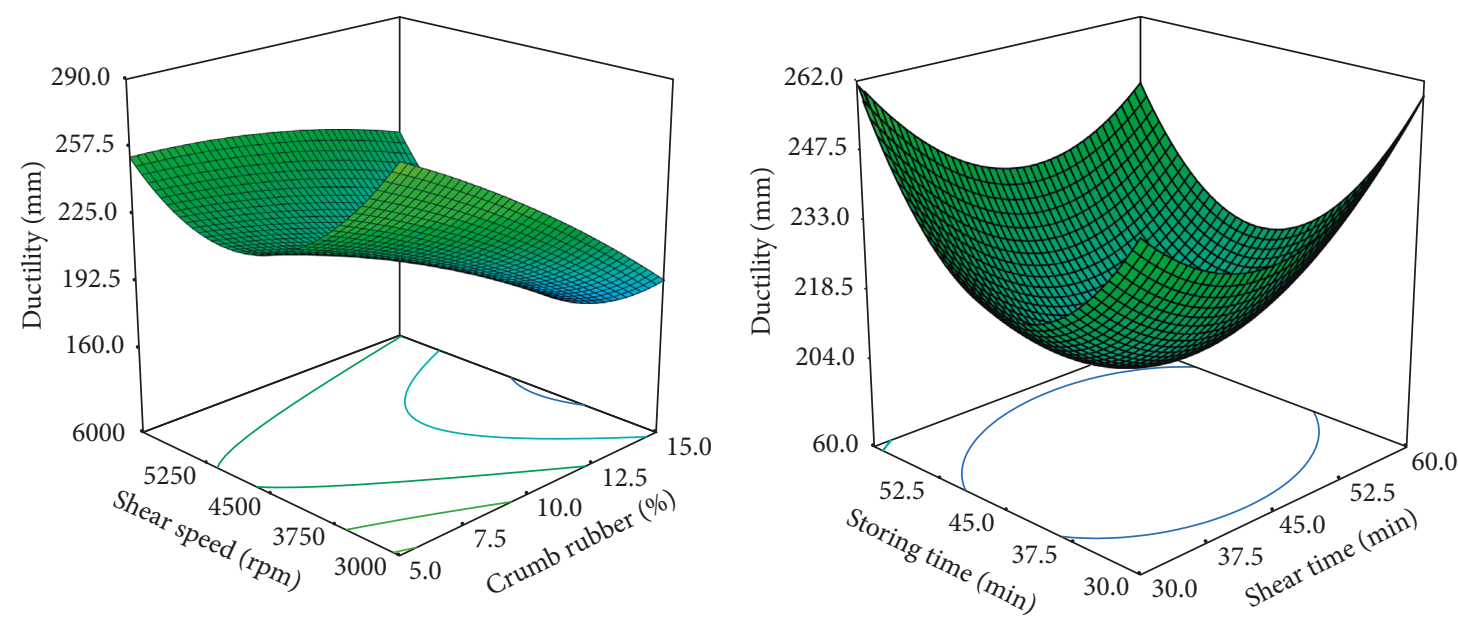

(a)

(b)

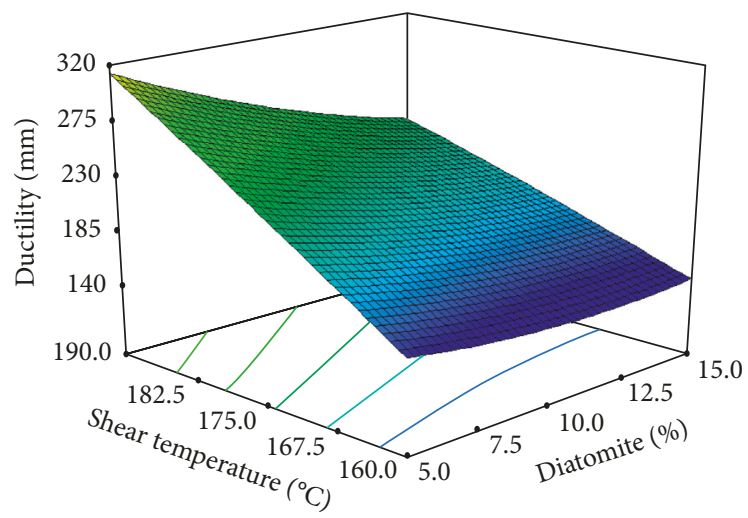

(c)

Figure 3: Response surface plots for the effect of preparation parameters on ductility. (a) Crumb rubber content $*$ shear speed, (b) storing time $*$ shear time, and (c) shear temperature $*$ diatomite content.

ductility. As for shear speed, shear time, and storing time, they can strength the gel-like structure and anchorage structure of asphalt and increase the stiffness of binder when their values are relatively lower. However, the stable structure will be destroyed when their values reach the critical points. Therefore, ductility decreases firstly and then increases with the increase of shear time, shear speed, and storing time.

\subsection{Viscosity}

3.5.1. Analysis of the Model for Viscosity. The viscosity model possessed satisfactory levels of $R^{2}(0.94)$, Adj. $R^{2}$ (0.87), and Adeq. precision (13.392), which were significant at $p<0.0001 . R^{2}$ and Adj. $R^{2}$ values of the model were higher than 0.8 , which revealed a close agreement between experimental results and predicted ones. An Adeq. precision of 13.392 indicated that the model can be used to navigate the design space.

As can be seen from the ANOVA results of independent variables for the viscosity model, the significant variables $(p<0.05)$ included $X_{1}, X_{3}, X_{4}, X_{5}, X_{25}, X_{46}$, and $X_{44}$. The reduced second-order model in terms of coded factors for viscosity was obtained by removing the insignificant variables:

$$
\begin{aligned}
Y_{4}= & 1907.75+1381.14 \times X_{1}+125.24 \times X_{3} \\
& -16.34 \times X_{4}-120.2 \times X_{5}-42.11 \times X_{25} \\
& +336.74 \times X_{46}+100.93 \times X_{44} .
\end{aligned}
$$

3.5.2. Effect of Preparation Parameters on Viscosity. As shown in Table 4, the most significant linear variables on viscosity include content of crumb rubber and shear time with $p \leq 0.0001$, followed by shear speed with $p<0.001$ and shear temperature with $p<0.05$. Meanwhile, the quadratic term of shear speed has a significant effect with $p<0.05$. Furthermore, the interaction terms of (shear speed) $*$ (storing time) and (diatomite content) $*$ (shear temperature) have significant effects on viscosity with $p<0.01$.

The relationships between preparation parameters and viscosity were demonstrated in $3 \mathrm{D}$ response surface plots, which are shown in Figure 4. As can be seen from the figure, the viscosities increase with the increase of diatomite concentration and crumb rubber concentration. However, they 


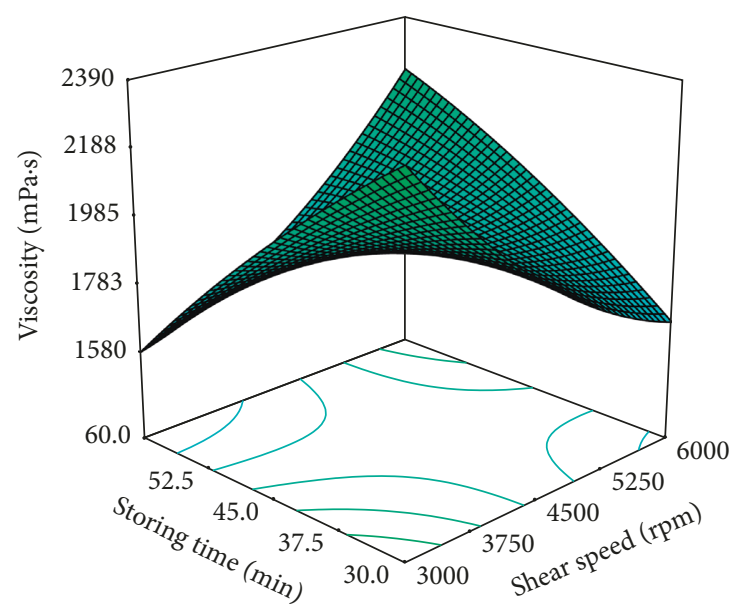

(a)

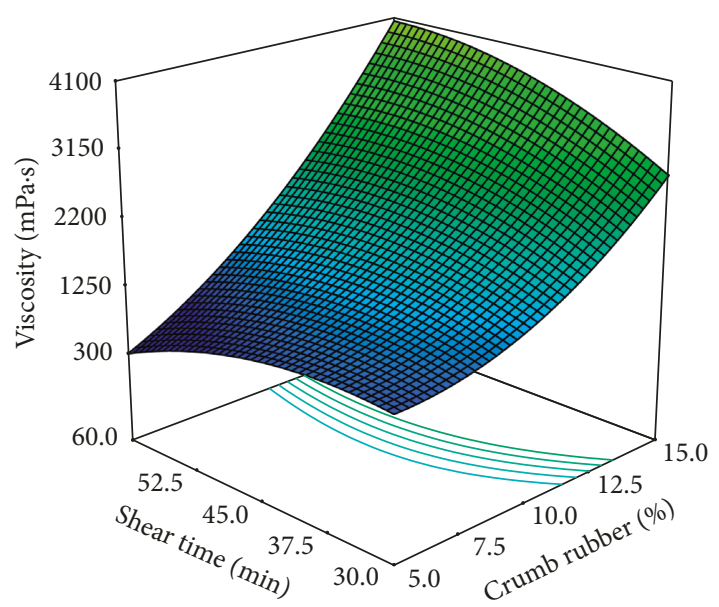

(b)

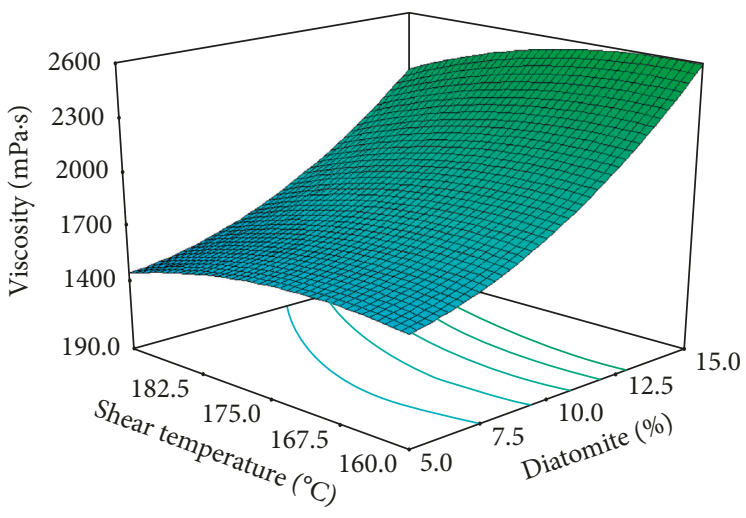

(c)

FIGURE 4: Response surface plots for the effect of preparation parameters on viscosity. (a) Storing time $*$ shear speed, (b) crumb rubber content $*$ shear time, and (c) shear temperature $*$ diatomite content.

present a declining trend with the increase of shear time, shear speed, shear temperature, and storing time.

This is because addition of diatomite and crumb rubber into asphalt can form a stable gel-like structure and an anchorage structure. The change in particle size and shape shortens the distances between particles, causing an increase in binder viscosity. If the values of shear temperature, shear speed, shear time, and storing time are too large, rubber particles will be broken down and dissolved into the liquid phase of binder. The crosslink bonds between particles will be destroyed, which will cause a reduction in binder viscosity.

\subsection{Elastic Recovery}

3.6.1. Analysis of the Model for Elastic Recovery. The elastic recovery model possessed satisfactory levels of $R^{2}(0.92)$, Adj. $R^{2}(0.84)$, and Adeq. precision (14.374), which were significant at $p<0.0001 . R^{2}$ and Adj. $R^{2}$ values of the model were higher than 0.8 , which revealed a close agreement between experimental results and predicted ones. An Adeq. precision of 14.374 indicated that the model can be used to navigate the design space.
As can be seen from the ANOVA results of independent variables for the elastic recovery model, the significant variables $(p<0.05)$ included $X_{1}, X_{2}, X_{12}, X_{13}, X_{46}, X_{11}$, and $X_{33}$. The reduced second-order model in terms of coded factors for elastic recovery was obtained by removing the insignificant variables:

$$
\begin{aligned}
Y_{5}= & 43.40+13.92 \times X_{1}+0.36 \times X_{2}+2.40 \times X_{12} \\
& +2.20 \times X_{13}+5.15 \times X_{46}+1.16 \times X_{11}-2.51 \times X_{33} .
\end{aligned}
$$

3.6.2. Effect of Preparation Parameters on Elastic Recovery. As shown in Table 4, the most significant linear variables on elastic recovery include content of crumb rubber and content of diatomite with $p<0.0001$. Meanwhile, the quadratic term of crumb rubber concentration has a significant effect with $p<0.01$, followed by shear speed with $p<0.05$. Furthermore, the interaction terms of (crumb rubber concentration) $*$ (shear time) have significant effects on elastic recovery with $p<0.01$, followed by (crumb rubber content) $*$ (diatomite content) and (shear speed) $*$ (storing time) with $p<0.05$. 


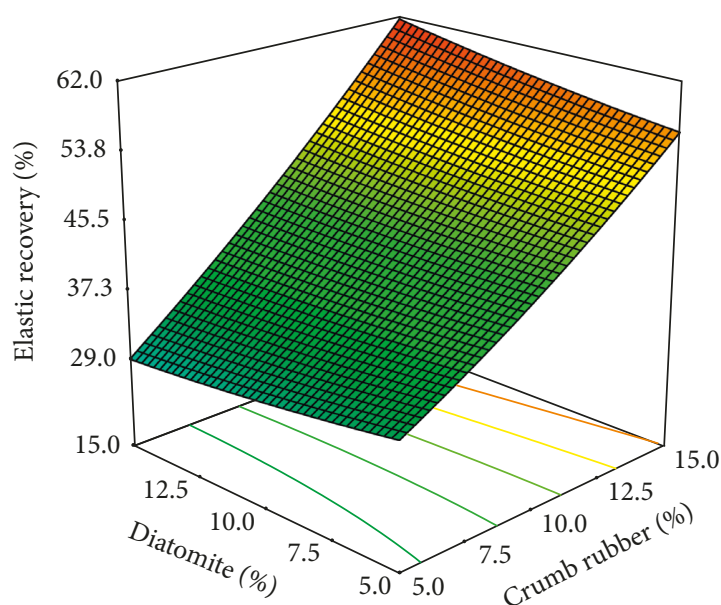

(a)

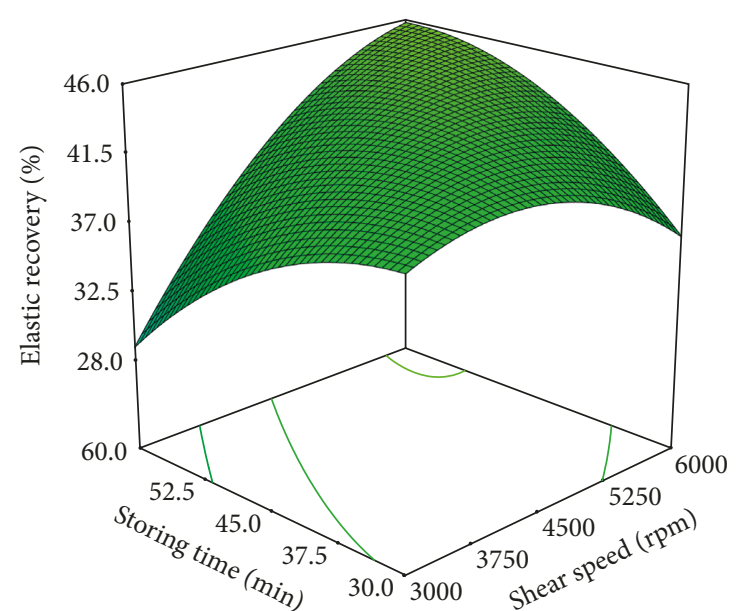

(b)

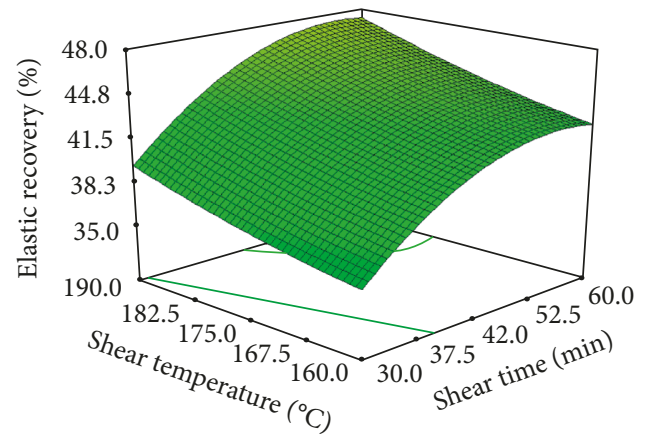

(c)

FIGURE 5: Response surface plots for the effect of preparation parameters on elastic recovery. (a) Crumb rubber content $*$ diatomite content, (b) storing time $*$ shear speed, and (c) shear temperature $*$ shear time.

The relationships between preparation parameters and elastic recovery were demonstrated in $3 \mathrm{D}$ response surface plots, which are shown in Figure 5. As can be seen from the figure, the elastic recovery increases with the increase of crumb rubber concentration and shear temperature. It increases with the increase of shear time and shear speed but at a decreasing rate. For the relationships of elastic recovery with storing time, they present the trend of increasing firstly and then decreasing slightly. Diatomite concentration can slightly increase the elastic recovery of binder. However, its effect is limited.

As can be seen from the results, the elastic recovery performance of the modified asphalt binder is mainly determined by crumb rubber concentration. The reasons lie in that crumb rubber possesses favorable elastic performance. Additions of crumb rubber into asphalt can strengthen the bonding effect of binder after swelling. The molecular force between particles is increased. Therefore, the ability of elastic recovery is improved. As for diatomite, it is a porous material without good elastic property. Its anchorage structure can enhance the elastic performance of binder to a certain extent. However, the effect is little.

\subsection{Penetration Index (PI)}

3.7.1. Analysis of the Model for PI. The PI model possessed satisfactory levels of $R^{2}(0.93)$, Adj. $R^{2}(0.85)$, and Adeq. precision (14.466), which were significant at $p<0.0001 . R^{2}$ and Adj. $R^{2}$ values of the model were higher than 0.8 , which revealed a close agreement between experimental results and predicted ones. An Adeq. precision of 14.466 indicated that the model can be used to navigate the design space.

As can be seen from the ANOVA results of independent variables for the PI model, the significant variables $(p<0.05)$ included $X_{1}, X_{2}, X_{14}, X_{23}, X_{46}, X_{22}, X_{33}$, and $X_{44}$. The reduced second-order model in terms of coded factors for PI was obtained by removing the insignificant variables:

$$
\begin{aligned}
Y_{6}= & -0.59+0.62 \times X_{1}+0.16 \times X_{2}-0.13 \times X_{14} \\
& +0.19 \times X_{23}+0.18 \times X_{46}+0.22 \times X_{22} \\
& +0.14 \times X_{33}+0.22 \times X_{44} .
\end{aligned}
$$

3.7.2. Effect of Preparation Parameters on Penetration Index (PI). As shown in Table 4, the most significant linear variables on PI are content of crumb rubber with $p<0.0001$, followed by content of diatomite with $p<0.001$. Meanwhile, the quadratic term of diatomite concentration and shear speed has a significant effect with $p<0.01$, followed by shear time with $p<0.05$. Furthermore, the interaction terms of (crumb rubber concentration) * (shear speed), (shear time) $*$ (diatomite content), and (shear speed)*(storing time) have significant effects on PI with $p<0.05$. 


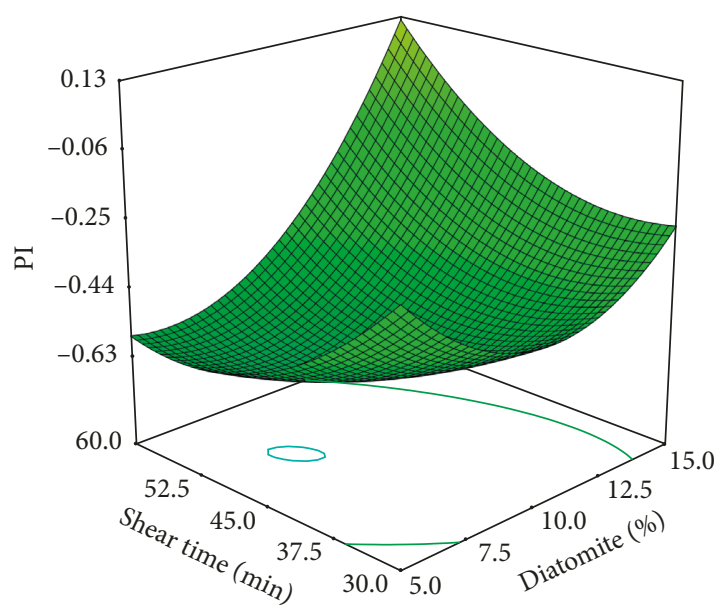

(a)

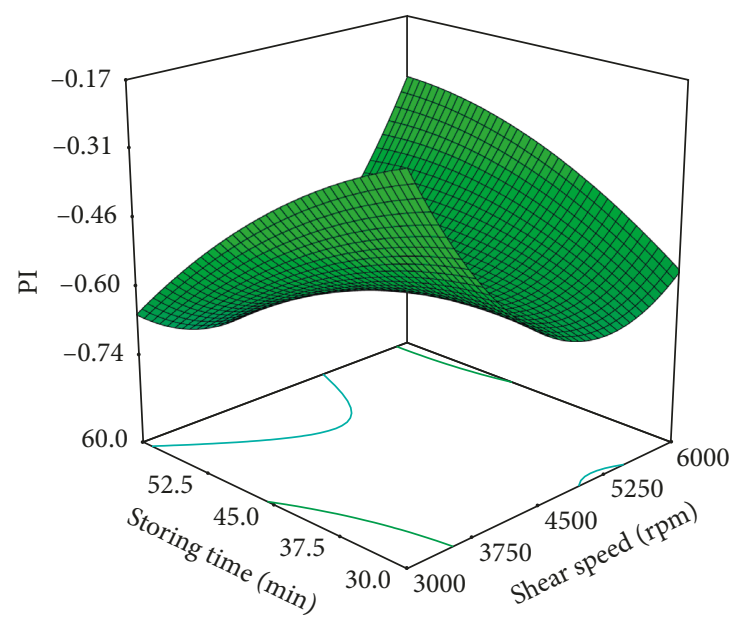

(b)

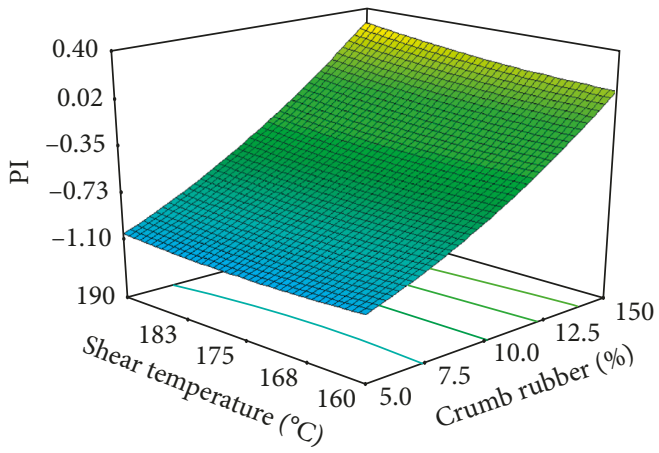

(c)

Figure 6: Response surface plots for the effect of preparation parameters on PI. (a) Shearing time * diatomite content, (b) storing time $*$ shear speed, and $(c)$ shear temperature $*$ crumb rubber content.

TABLE 5: Optimum preparation parameters and corresponding predicted and experimental results.

\begin{tabular}{lccccc}
\hline Factors & $X_{1}$ & $X_{2}$ & $X_{3}$ & $X_{4}$ & $X_{5}$ \\
\hline Optimum value & 13.8 & 6.2 & 55 & 5300 & 183 \\
Responses & $Y_{1}$ & $Y_{2}$ & $Y_{3}$ & $Y_{4}$ & $Y_{5}$ \\
Predicted results & 54.15 & 55.17 & 307.4 & 2708 & 67.63 \\
Experimental results & 54.96 & 54.56 & 296.6 & 2814 & 68.64 \\
Relative error (\%) & 1.5 & 1.1 & 3.5 & 3.9 & 1.5 \\
\hline
\end{tabular}

The relationships between preparation parameters and PI were demonstrated in $3 \mathrm{D}$ response surface plots, which are shown in Figure 6. As can be seen from the figure, the PI increases with the increase of crumb rubber concentration. It remains relatively stable before $8-10 \%$ of diatomite concentration and increases after that. The relationships of PI with shear speed and shear time present the trend of decreasing firstly and then increasing. PI increases with the increase of shear temperature with little amplitude.

The results reveal that addition of crumb rubber and diatomite into asphalt can effectively improve its temperature stability. This is mainly because of the gel-like structure and anchorage structure. As for shear time, shear speed, shear temperature, and swelling time, their influences on temperature stability of binder are lower than on diatomite concentration and crumb rubber concentration.

3.8. Multiresponse Optimization. Preparation parameters present different effects on properties of crumb rubber and diatomite compound-modified asphalt binder. In order to obtain the modified asphalt binder with satisfactory properties, multiresponse optimization is conducted using the RSM. Taking the modified asphalt used in the cold region, for example, the corresponding optimization criteria are determined according to JTG F40-2004 [35] and "Guide for Design and Construction of Asphalt Rubber and Mixtures" [36] in China. The optimization was carried out by maximizing the softening point, ductility, elastic recovery, and minimizing penetration, while the viscosity is between 1000 and $3000 \mathrm{mPa} \cdot \mathrm{s}$. Viscosity should not be too high because of the workability of modified asphalt binder. PI is not considered because it can be calculated based on penetration and softening point results according to (2). The optimization process is determined and listed in Table 5 .

In order to verify the equations as well as the optimum data obtained by the RSM, experimental tests were conducted using the same preparation parameters listed in Table 5. The experimental results are obtained and also shown in 
Table 5. As shown in this table, the predicted and experimental results possess favorable consistency.

\section{Conclusions}

In this paper, crumb rubber and diatomite compoundmodified asphalt binder was prepared. The effects of preparation parameters on properties of modified asphalt binder were investigated, and multiresponse optimization was conducted using the response surface method. The following conclusions can be obtained:

(1) Response surface method is a suitable method for preparation parameter analysis and optimization of crumb rubber and diatomite compound-modified asphalt binder, which can effectively reduce the number of groups.

(2) Crumb rubber concentration presents significant effects on all of the asphalt properties used in this study. Softening points, viscosity, elastic recovery, and PI increase, while penetration and ductility decrease with the increase of crumb rubber concentration. It reveals that the addition of crumb rubber can improve the high temperature susceptibility, viscosity, and elastic recovery ability of binder.

(3) Diatomite concentration presents significant effects on all of the asphalt properties except elastic recovery. Softening points, viscosity, and PI increase, while penetration and ductility decrease with the increase of diatomite concentration, which presents little influence on elastic recovery of binder.

(4) Shear temperature presented significant effects on penetration, softening point, viscosity, and ductility. Shear speed, shear time, and storing time have similar effects on binder properties because of their similar mechanism of action.

(5) Based on the model obtained from the RSM, optimized preparation parameters corresponding to specific criteria can be determined, which possessed favorable accuracy compared with experimental results.

Investigation of other properties such as bending beam rheometer (BBR) and dynamic shear rheometer (DSR) tests of crumb rubber and diatomite compound-modified asphalt binder needs to be conducted in the near future.

\section{Conflicts of Interest}

The authors declare that they have no conflicts of interest.

\section{Acknowledgments}

The authors express their appreciation for the financial support of the National Natural Science Foundation of China under Grant no. 51408258; the China Postdoctoral Science Foundation funded projects (nos. 2014M560237 and 2015T80305); the Fundamental Research Funds for the
Central Universities (JCKYQKJC06); and Science and Technology Development Program of Jilin Province.

\section{References}

[1] V. W. Y. Tam and C. M. Tam, "A review on the viable technology for construction waste recycling," Resources, Conservation and Recycling, vol. 47, no. 3, pp. 209-221, 2006.

[2] M. N. Amin, M. I. Khan, and M. U. Saleem, "Performance evaluation of asphalt modified with municipal wastes for sustainable pavement construction," Sustainability, vol. 8, no. 12, p. 949, 2016.

[3] D. L. Presti, "Recycled tyre rubber modified bitumens for road asphalt mixtures: a literature review," Construction and Building Materials, vol. 49, pp. 863-881, 2013.

[4] M. C. Zanetti, S. Fiore, B. Ruffino, E. Santagata, D. Dalmazzo, and M. Lanotte, "Characterization of crumb rubber from endof-life tyres for paving applications," Waste Management, vol. 45, pp. 161-170, 2015.

[5] A. Farina, M. C. Zanetti, E. Santagata, and G. A. Blengini, "Life cycle assessment applied to bituminous mixtures containing recycled materials: crumb rubber and reclaimed asphalt pavement," Resources, Conservation and Recycling, vol. 117, pp. 204-212, 2017.

[6] I. Bartolozzi, S. Mavridou, F. Rizzi, and M. Frey, "Life cycle thinking in sustainable supply chains: the case of rubberized asphalt pavement," Environmental Engineering and Management Journal, vol. 14, no. 5, pp. 1203-1215, 2015.

[7] A. D. La Rosa, G. Recca, D. Carbone et al., "Environmental benefits of using ground tyre rubber in new pneumatic formulations: a life cycle assessment approach," Proceedings of the Institution of Mechanical Engineers, Part L: Journal of Materials: Design and Applications, vol. 229, no. 4, pp. 309-317, 2013.

[8] B. Yu, L. Jiao, F. Ni, and J. Yang, "Evaluation of plastic-rubber asphalt: engineering property and environmental concern," Construction and Building Materials, vol. 71, pp. 416-424, 2014.

[9] F. Moreno, M. Sol, J. Martín, M. Pérez, and M. C. Rubio, “The effect of crumb rubber modifier on the resistance of asphalt mixes to plastic deformation," Materials and Design, vol. 47, pp. 274-280, 2013.

[10] S. K. Palit, K. S. Reddy, and B. B. Pandey, "Laboratory evaluation of crumb rubber modified asphalt mixes," Journal of Materials in Civil Engineering, vol. 16, no. 1, pp. 45-53, 2004.

[11] O. Xu, F. Xiao, S. Han, S. N. Amirkhanian, and Z. Wang, "High temperature rheological properties of crumb rubber modified asphalt binders with various modifiers," Construction and Building Materials, vol. 112, pp. 49-58, 2016.

[12] K. L. N. N. Puga and R. C. Williams, "Low temperature performance of laboratory produced asphalt rubber (AR) mixes containing polyoctenamer," Construction and Building Materials, vol. 112, pp. 1046-1053, 2016.

[13] T. Wang, F. Xiao, S. Amirkhanian, W. Huang, and M. Zheng, "A review on low temperature performances of rubberized asphalt materials," Construction and Building Materials, vol. 145, pp. 483-505, 2017.

[14] P. Cong, S. Chen, and H. Chen, "Effects of diatomite on the properties of asphalt binder," Construction and Building Materials, vol. 30, pp. 495-499, 2012.

[15] Y. Tan, Z. Lei, and X. Zhou, "Investigation of low-temperature properties of diatomite-modified asphalt mixtures," Construction and Building Materials, vol. 36, pp. 787-795, 2012. 
[16] Y. Cheng, J. Tao, Y. Jiao et al., "Influence of the properties of filler on high and medium temperature performances of asphalt mastic," Construction and Building Materials, vol. 118, pp. 268-275, 2016.

[17] Q. Guo, L. Li, Y. Cheng, Y. Jiao, and C. Xu, "Laboratory evaluation on performance of diatomite and glass fiber compound modified asphalt mixture," Materials and Design, vol. 66, pp. 51-59, 2015.

[18] P. Cong, N. Liu, Y. Tian, and Y. Zhang, "Effects of long-term aging on the properties of asphalt binder containing diatoms," Construction and Building Materials, vol. 123, pp. 534-540, 2016.

[19] H. Liu, L. Fu, Y. Jiao, J. Tao, and X. Wang, "Short-term aging effect on properties of sustainable pavement asphalts modified by waste rubber and diatomite," Sustainability, vol. 9, no. 12, p. 996, 2017.

[20] C. Fang, X. Qiao, R. Yu et al., "Influence of modification process parameters on the properties of crumb rubber/EVA modified asphalt," Journal of Applied Polymer Science, vol. 133, no. 27, 2016.

[21] H. Yu, Z. Leng, Z. Zhou, K. Shih, F. Xiao, and Z. Gao, "Optimization of preparation procedure of liquid warm mix additive modified asphalt rubber," Journal of Cleaner Production, vol. 141, pp. 336-345, 2017.

[22] X. Shu and B. Huang, "Recycling of waste tire rubber in asphalt and Portland cement concrete: an overview," Construction and Building Materials, vol. 67, pp. 217-224, 2014.

[23] S. Kedarisetty, K. P. Biligiri, and J. B. Sousa, "Advanced rheological characterization of reacted and activated rubber (RAR) modified asphalt binders," Construction and Building Materials, vol. 122, pp. 12-22, 2016.

[24] Q. Wang, S. Li, X. Wu, S. Wang, and C. Ouyang, "Weather aging resistance of different rubber modified asphalts," Construction and Building Materials, vol. 106, pp. 443-448, 2016.

[25] J. Peralta, H. M. Silva, L. Hilliou, A. V. Machado, J. Pais, and R. C. Williams, "Mutual changes in bitumen and rubber related to the production of asphalt rubber binders," Construction and Building Materials, vol. 36, pp. 557-565, 2012.

[26] J. C. Munera and E. A. Ossa, "Polymer modified bitumen: optimization and selection," Materials and Design, vol. 62, pp. 91-97, 2014.

[27] L. H. Li, Road Engineering Materials, China Communications Press, Beijing, China, 5th edition, 2010.

[28] M. L. Huang, Y. H. Hung, and Z. S. Yang, "Validation of a method using Taguchi, response surface, neural network, and genetic algorithm," Measurement, vol. 94, pp. 284-294, 2016.

[29] I. Kaymaz and C. A. McMahon, "A response surface method based on weighted regression for structural reliability analysis," Probabilistic Engineering Mechanics, vol. 20, no. 1, pp. 11-17, 2005.

[30] O. Rezaifar, M. Hasanzadeh, and M. Gholhaki, "Concrete made with hybrid blends of crumb rubber and metakaolin: optimization using response surface method," Construction and Building Materials, vol. 123, pp. 59-68, 2016.

[31] H. İ. Odabaş and I. Koca, "Application of response surface methodology for optimizing the recovery of phenolic compounds from hazelnut skin using different extraction methods," Industrial Crops and Products, vol. 91, pp. 114-124, 2016.

[32] M. H. Esfe, H. Hajmohammad, R. Moradi, and A. A. A. Arani, "Multi-objective optimization of cost and thermal performance of double walled carbon nanotubes/water nanofluids by NSGA-II using response surface method," Applied Thermal Engineering, vol. 112, pp. 1648-1657, 2017.

[33] Y. Song, J. Che, and Y. Zhang, "The interacting rule of diatomite and asphalt groups," Petroleum Science and Technology, vol. 29, no. 3, pp. 254-259, 2011.

[34] Y. Cheng, J. Tao, Y. Jiao, Q. Guo, and C. Li, "Influence of diatomite and mineral powder on thermal oxidative ageing properties of asphalt," Advances in Materials Science and Engineering, vol. 2015, Article ID 947834, 10 pages, 2015.

[35] JTG F40-2004, Technical Specifications for Construction of Highway Asphalt Pavements, Research Institute of Highway Ministry of Transport, Beijing, China, 2004, in Chinese.

[36] China Communications Press, Guide for Design and Construction of Asphalt Rubber and Mixtures, China Communications Press, Beijing, China, 2009, in Chinese. 


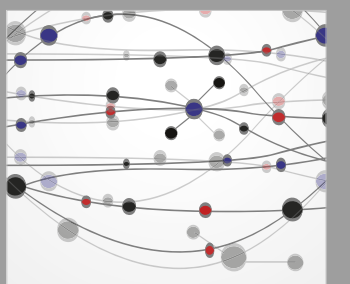

The Scientific World Journal
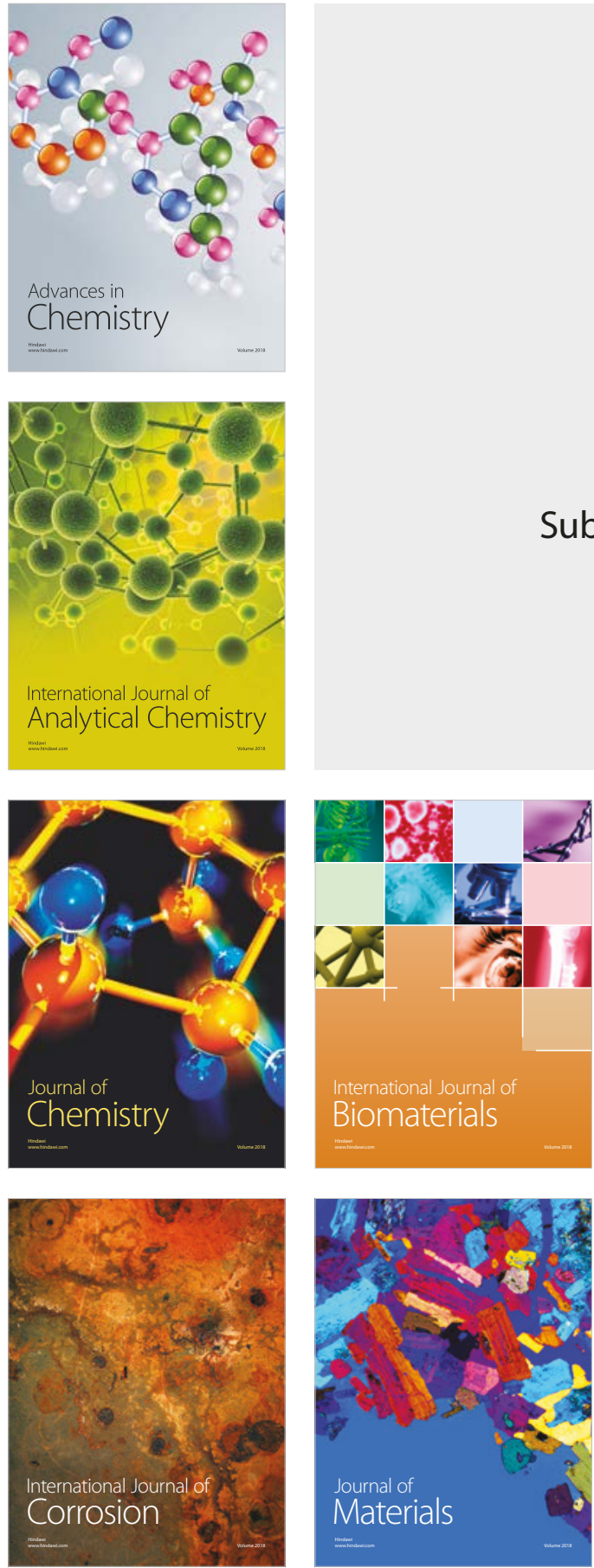

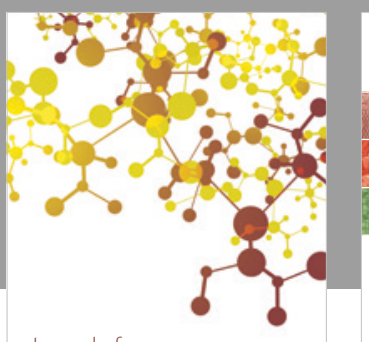

Journal of

Applied Chemistry
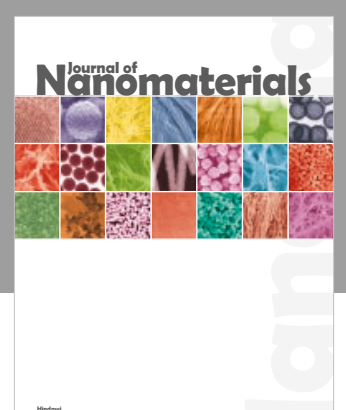

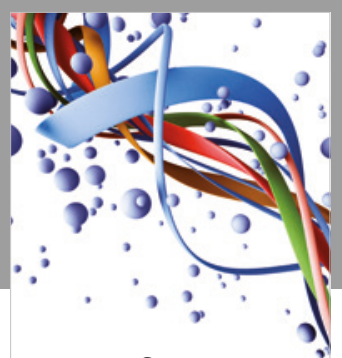

Scientifica

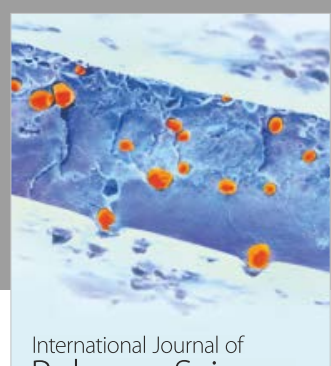

Polymer Science

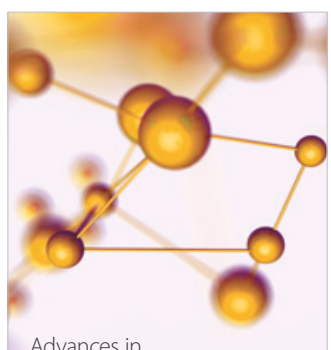

Physical Chemistry
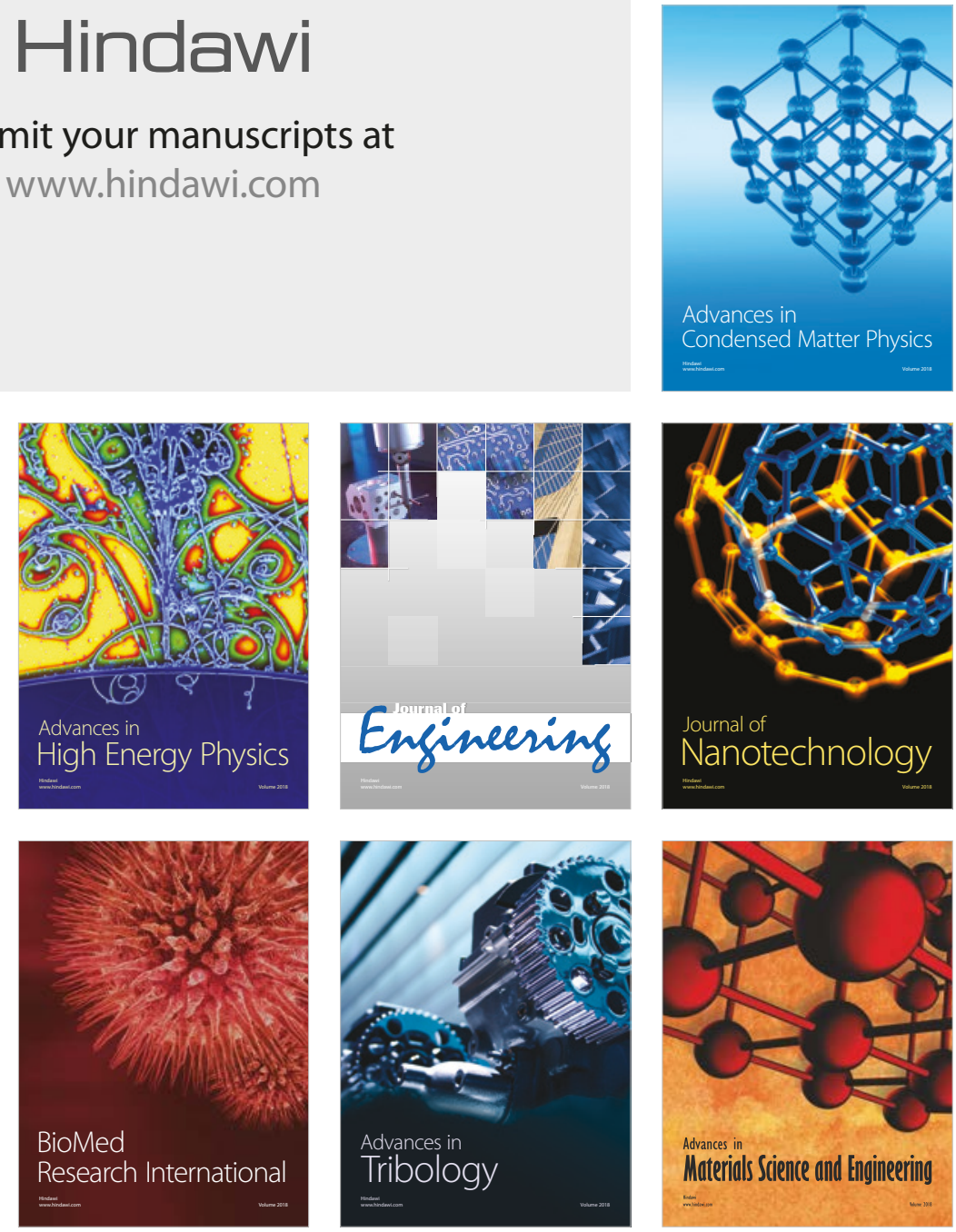